\title{
Examination of the Burnout Levels of Basketball Players in Terms of Gender, Age and Experience
}

\author{
Turhan Toros $^{1}$, Çağatay Dereceli ${ }^{2}$, Ali İlhan Barut ${ }^{3}$ \\ ${ }^{1}$ Mersin University, Department of Physical Education and Sport, Turkey \\ ${ }^{2}$ Aydın Adnan Menderes Üniversites, Department of Physical Education and Sport, Turkey \\ ${ }^{3}$ M. Sc. Psychologist-PhD Student, Mersin University, Department of Physical Education and Sport, Turkey \\ Correspondence: Turhan Toros, Mersin University, Department of Physical Education and Sport, Turkey.
}

Received: September 21, 2017

Accepted: November 20, 2017

Online Published: November 23, 2017

doi:10.11114/jets.v5i12.2817

URL: https://doi.org/10.11114/jets.v5i12.2817

\begin{abstract}
The purpose of this study is to examine the burnout levels of basketball players in terms of gender, age and experience. A total of 270 (124 female and 146 male) basketball players (age mean $x=23.07 \pm 1.28$ years) participated in the study. Maslach's Burnout Inventory was developed by Maslach and Jackson (1981) and adapted to Turkish by Ergin (1992) was used to measure the burnout levels of basketball players for collecting data. The data were analyzed with SPSS program. The Cronbach's alpha coefficient was calculated to test the internal consistency of the scale. The Mann-Whitney U test was used for paired group comparisons. The Kruskal Wallis H test was used for the multiple group comparisons. When Mann Whitney U test results were examined, Emotional Exhaustion $(\mathrm{p}=.063, \mathrm{p}>.05)$, Depersonalization $(\mathrm{p}=.498, \mathrm{p}>.05)$ and Personal Accomplishment $(\mathrm{p}=.599, \mathrm{p}>.05)$, there was no significant difference between male and female basketball players according to gender. According to Kruskall Wallis $\mathrm{H}$ test results, the variables of emotional exhaustion $(\mathrm{p}=.162, \mathrm{p}>.05)$, Depersonalization $(\mathrm{p}=.319, \mathrm{p}>.05)$ and Personal Accomplishment $(\mathrm{p}=.284, \mathrm{p}>.05)$ no significant difference was observed. According to Kruskall Wallis $\mathrm{H}$ test results, there was no significant difference in Personal Accomplishment $(p=.674, p>.05)$ sub-dimensions according to experience variable. However, significant differences were found in the subscales of Emotional Exhaustion $(p=.002, p$ $<.05)$ and Depersonalization $(\mathrm{p}=.033, \mathrm{p}<.05)$ compared to the experience variable. As a result, the level of burnout is important for the experience of basketball players.
\end{abstract}

Keywords: basketball, basketball coach, burnout, emotional exhaustion, depersonalization and personal accomplishment

\section{Introduction}

Burnout has been described as an excessive demand on energy, strength and resources resulting in exhaustion (Freudenberger, 1975). Originally, burnout was introduced into the discipline of psychology as a syndrome affecting human healthcare professionals in the mid- to late-1970s (Freudenberger, 1975). "Burnout" is a syndrome that leads to physical, emotional and mental fatigue, which often occur in individuals who work in or work for people (Akcamete, Kaner and Sucuoğlu, 2001). The concept of burnout has been started to be studied by researchers since the 1970s (Budak and Sürgevil, 2005). When the variables that emerged as a result of the pressure on the workers in the production and service sectors are not controlled over time, the burnout syndrome constitutes a certain psychology in individuals. This situation, which is seen in the upper levels in individuals causes burnout syndrome (Demirtas and Güneş, 2002). The Maslach Burnout Inventory (MBI) was introduced in 1981 as a manner of measuring burnout as well as its components of emotional exhaustion, depersonalization, and personal accomplishment (Maslach \& Jackson, 1981). A number of variables contribute to a healthcare professional's risk of developing burnout including patient population type, work relationships, work schedule, time involved in profession, job attitudes, lack of control, lack of social support, lack of role clarity, difficult interactions with patients' families, work overload, low self-esteem, organizational dysfunction, and interdisciplinary conflict (Marshall \& Kasman, 1980; Pines \& Maslach, 1978; Schuster, Nelson, \& Quisling, 1984; Wolfe, 1981). In the workplace, burnout may result in decreased job performance, decreased productivity, loss of concern for patients and withdrawal from work (Schuster et al., 1984; Wolfe, 1981). Building on the current knowledge base and extant athlete burnout theory, continued research is needed which examines the 
relationship of athlete burnout of basketball players in different terms. Existing research has suggested factors and covariates related to athlete burnout including motivation, starting status, and sport experience. However, research on the association between athletic injury and athlete burnout is still in its infancy and methodologically limited. For example, current studies have utilized work based as opposed to a sport-based burnout measure. In the past two decades, research related to burnout has transcended the workplace context and expanded to include athletes. Adapted from burnout occurring in the workplace, athlete burnout (AB) is comprised of three dimensions: (1) emotional and physical exhaustion; (2) reduced sense of sport accomplishment; and (3) sport devaluation. Empirical research on the prevalence of athlete burnout is continuing to develop. There is limited knowledge regarding the prevalence of burnout in athletes, with current research estimating the prevalence to be less than $10 \%$. Both individual and organization factors have been theorized to contribute to burnout in athletes including psychological stress and stressors related to sport, unidimensional identification as an athlete, external control, and feelings of entrapment in sport. Continued examination of the relationship of athlete burnout with empirically specified antecedents will further the understanding of this maladaptive experience for athletes

When non-sports literature is searched, basically human motivation is the emotions that keep people alive and enable them to continue their generation towards pressure of nature. The concept of stress at the essential of these emotions is basically to escape from the hunter, to protect the younger, to struggle with hunger, to preserve the hierarchy in the social environment and so on. as a solution to many basic problems such as the kind of motivation. Higher working status of society as a result of liberal economic progression. The expectation from life and working life stresses the individual under a certain pressure of stress. If stress, which is a source of motivation is not controlled and evaluated by the organization over time, depression or depression can not be controlled as a result of stress in the case of burnout syndrome psychologically and clinically emerges. "Burnout" term is the long-term abandonment of the sport from the work that the individual have doing. During this period, the athlete does not feel excited to practice or compete and evaluating him/herself as unsuccessful and inadequate. In time, first he/she moves away from sport then social life.

Athlete burnout is a multidimensional psychological syndrome characterized by emotional and physical exhaustion, reduced sense of accomplishment, and sport devaluation (Raedeke, 1997; Raedeke \& Smith, 2001). Emotional and physical exhaustion is linked to fatigue from the mental and physical demands of sport training and competition. Reduced sense of accomplishment is an inefficacy and tendency to evaluate oneself negatively regardless of sport performance or accomplishment, which is linked to an athlete's perception of athletic ability and individual achievement standards. Sport devaluation is resentment towards sport as well as the loss of interest in sport, which is linked to a development of an undesirable attitude toward sport participation and a decline in sport performance quality (Raedeke, 1997; Raedeke \& Smith, 2001, 2009). This operational definition has guided empirical efforts to understand this complex psychological phenomenon in athlete populations. Research has found athlete burnout to be associated with a variety of physiological and psychological antecedents. Responses commonly associated with athlete endorsement of burnout-related perceptions include anxiety, depression, tension, altered sleep patterns, susceptibility to illness, fatigue, lowered self-esteem, apathy, and depression (Goodger et al., 12 2007; Silva III, 1990; Smith, 1986). Moreover, the symptoms of burnout itself can present in a number of forms including inappropriate behavior, difficulty interacting with others, emotional and physical isolation, emotional and physical withdrawal, decreased performance, a change in values and beliefs, substance abuse or a sense of helplessness (Lemyre et al., 2007; Silva III, 1990; Smith, 1986). Due to potentially different etiologies across athletes, a variety of theories have been utilized to aid in the understanding of this maladaptive experience and its associated responses.

According to Pines and Aranson (1988); the main reason for your exhaustion is the training environment which keeps the athlete under constant emotional pressure. In this context, the type of pressure, it's content and context have a significant factor. Burnout syndrome also refers to physical and mental exhaustion due to lack of motivation (Surgevil, 2005). According to Maslach "Burnout"; emotional exhaustion, depersonalization, and lack of personal accomplishment sense are identified as three-dimensional syndromes (Yıldırım, 1996).

Emotional exhaustion, especially with intense training tempo and conflicting dimensions puts the athlete under intense stress (Kervanc1, 2013). According to Maslach, the most important dimension of exhaustion is emotional exhaustion. It is known that expectations in employees are directly related to emotional exhaustion. According to many researchers, the dimension of emotional exhaustion is the dimension of exhaustion that can be observed more clearly than the other two dimensions (Maslach and Jackson 1981)

On the dimension of depersonalization, distant and apathetic behaviors constitute the second dimension of burnout syndrome. Individual exhibits behavior as if they are an "object" (Sarıkaya, 2007).

Personal accomplishment means that the individual evaluates him/herself as inadequate and unsuccessful at his/her work (Wright and Bonett, 1997). The individual feels that he can not be successful personally, he starts to believe that 
nobody likes him and develops feelings of inadequate communication with his colleagues (Çiper, 2006).

Research has argued that both men and women can experience burnout. Athletes from individual sports display burnout levels, comparing to athletes from teams sports, because of the nature of individual sports. Young athletes experience burn out because they lack coping skills but amateur athletes become highly exhausted and tend to evaluated their sport because they become entrapment to their sport(Gould et all., 1996).

All this information has become important to the emotion of exhaustion at basketball players. At the same time, the question of what might be the cause of athletes' burnout has emerged.

\subsection{Purpose of the Study}

The purpose of this study is to examine the burnout levels of basketball players in terms of gender, age and experience.

The following objectives have been sought for the realization of the purpose.

- Is there a significant difference between basketball players' burnout levels (emotional exhaustion depersonalization, personal accomplishment) and gender?

- Is there a significant difference between basketball players' burnout levels (emotional exhaustion depersonalization, personal accomplishment) and age?

- Is there a significant difference between basketball players' burnout levels (emotional exhaustion depersonalization, personal accomplishment) and experience?

\section{Method}

\subsection{Research Model}

This research is a descriptive screening study. "The research that consists of the collection of data in order to determine the specific characters of a group is called screening" (Büyüköztürk, Çakmak, Akgün, Karadeniz and Demirci, 2009). "Screening models are research approaches that aim to describe a past or current situation as in the way they exist" (Ersoy, 2013).

\subsection{Study Group}

A total of 270 (124 female and 146 male) basketball players (age mean $\mathrm{x}=23.07 \pm 1.28$ years) participated in the study. This study is limited to women and men over 18 years who play basketball on amateur teams in Türkiye.

\subsection{Data Collection and Analysis}

Maslach's Burnout Inventory was developed by Maslach and Jackson (1981) and adapted to Turkish by Ergin (1992) was used to measure the burnout levels of basketball players. This scale consists of three subscales. These scales are; "Emotional exhaustion contains 9 items," depersonalization contains 5 items, and personal accomplishment contains 8 items. Each item in the scale is a 7-point Likert-type measure that rated from 0 to 6 . The emotional exhaustion subscale describes the feelings of being exhausted and overloaded by one's occupation or work. The depersonalization subscale defines their behavior in a way that they feel deprived of their service. The personal accomplishment subscale defines self-sufficiency and achievement (Çam, 1992).

The reliability of the scale was examined in two methods by Ergin (1992). The first is calculation of the internal consistency of scale. Internal consistency coefficients of the data are as follows: Emotional exhaustion .83, Depersonalization .65, Personal accomplisment .72. Reliability was also examined by test-retest method. 99 cases were reached after 2-4 weeks from the first application. Test retest reliability coefficients for subscales of the scale were: Emotional exhaustion .83, Depersonalization .72, Personal accomplishment .67. As a result of the reliability analysis conducted for this research, emotional exhaustion $\alpha=0.75$, depersonalization $\alpha=0.54$, personal accomplishment $\alpha=$ 0.72 and total burnout $\alpha=0.81$. The construct validity of Maslach's Burnout Inventory was examined by examining factor structure. Factor analysis revealed 5 natural factors at first and it was seen that they were aggregated in 3 factors. It has been re-evaluated with varimax rotation, as recommended by Maslach and Jackson (1981), as practiced by other researchers. As a result, three factors emotional exhaustion, depersonalization and personal accomplishment have emerged (Ergin, 1992). As a result of the internal consistency analysis, the alpha coefficients were calculated as: Emotional exhaustion .80, Depersonalization .77, Personal accomplishment .81.

The scale was applied to the athletes before their training. The athletes were volunteers who participate in this study. Obligatory information has been given to the participants on purpose of the study and privacy.The data were analyzed with SPSS program. The Cronbach's alpha coefficient was calculated to test the internal consistency of the scale. Kolmogorov-Smirnov normality test was performed because the sample size was greater than 50 in the survey. Test results did not show normal distribution. So The Mann-Whitney U test was used for paired group comparisons and The Kruskal Wallis $\mathrm{H}$ test was used for the multiple group comparisons. 


\section{Results}

Table 1. Analysis of burnout levels of basketball players in terms of gender (Mann Whitney U Test)

\begin{tabular}{|c|c|c|c|c|c|c|}
\hline & Gender & $\mathrm{n}$ & Means & $\mathrm{U}$ & $\mathrm{Z}$ & $\mathrm{p}$ \\
\hline \multirow{3}{*}{$\begin{array}{l}\text { Emotional } \\
\text { Exhaustion }\end{array}$} & Male & 146 & 128.61 & \multirow{3}{*}{$\begin{array}{l}7361.50 \\
0\end{array}$} & \multirow[t]{3}{*}{-1.754} & \multirow[t]{3}{*}{.063} \\
\hline & Female & 124 & 111.67 & & & \\
\hline & Total & 270 & & & & \\
\hline \multirow{3}{*}{ Depersonalization } & Male & 146 & 118.30 & \multirow{3}{*}{$\begin{array}{l}8000.50 \\
0\end{array}$} & \multirow[t]{3}{*}{-.621} & \multirow[t]{3}{*}{.498} \\
\hline & Female & 124 & 124.69 & & & \\
\hline & Total & 270 & & & & \\
\hline \multirow{3}{*}{ Personal Accomplishment } & Male & 146 & 119.58 & \multirow{3}{*}{$\begin{array}{l}8146.50 \\
0\end{array}$} & \multirow[t]{3}{*}{-.430} & \multirow[t]{3}{*}{.599} \\
\hline & Female & 124 & 123.21 & & & \\
\hline & Total & 270 & & & & \\
\hline
\end{tabular}

Examination of the burnout level of basketball players in terms of gender is shown in Table 1. According to the results of Mann Whitney $U$ test, there is no significant difference between male and female basketball players in terms of gender in the subscales of Emotional Exhaustion $(\mathrm{p}=.063, \mathrm{p}>.05)$, Depersonalization $(\mathrm{p}=.498, \mathrm{p}>.05)$ and Personal Accomplishment ( $\mathrm{p}=.599, \mathrm{p}>.05)$

Table 2. Analysis of burnout levels of basketball players in terms of age. (Kruskall Wallis H Test)

\begin{tabular}{llllll}
\hline & Age & $\mathrm{n}$ & Means & $x^{2}$ & $\mathrm{p}$ \\
\hline \multirow{3}{*}{ Emotional } & $21-22$ years & 158 & 126.86 & 3.712 & .162 \\
Exhaustion & $23-24$ years & 87 & 114.21 & & \\
& $24+$ over & 25 & 112.09 & & \\
& Total & 270 & & & \\
& $21-22$ years & 158 & 127.81 & 2.230 & .319 \\
Depersonalization & $23-24$ years & 87 & 132.59 & & \\
& $24+$ over & 25 & 156.81 & & .284 \\
& Total & 270 & & & \\
Personal Accomplishment & $21-22$ years & 158 & 130.55 & & \\
& $23-24$ years & 87 & 126.25 & & \\
& $24+$ over & 25 & 158.59 & & \\
\hline
\end{tabular}

According to the results of Kruskall Wallis $\mathrm{H}$ test, there is no significant difference in terms of age in the subscales of Emotional Exhaustion $(\mathrm{p}=.162, \mathrm{p}>.05)$, Depersonalization $(\mathrm{p}=.319, \mathrm{p}>.05)$ and Personal Accomplishment $(\mathrm{p}=.284$, p> .05).

Table 3. Analysis of burnout levels of basketball players in terms of experience year (Kruskall Wallis H Testi).

\begin{tabular}{llllll}
\hline & $\begin{array}{l}\text { Experience } \\
\text { Year }\end{array}$ & $\mathrm{n}$ & Means & $x^{2}$ & $\mathrm{p}$ \\
\hline \multirow{3}{*}{ Emotional } & 1-4 years & 178 & 128.92 & 11.510 & .002 \\
Exhaustion & 5-8 years & 35 & 81.56 & & \\
& 9+ over & 57 & 114.90 & & \\
& Total & 270 & & & \\
1-5 years & 178 & 122.50 & 5.811 & .033 \\
Depersonalization & 6-10 years & 35 & 87.72 & & \\
& 11+ over & 57 & 130.76 & & \\
& Total & 270 & & & \\
& 1-5 years & 178 & 122.51 & .555 & .674 \\
Personal Accomplishment & 6-10 years & 35 & 110.04 & & \\
& 11+ over & 57 & 120.83 & & \\
& Toplam & 270 & & & \\
\hline
\end{tabular}

Examination of the burnout level of basketball players in terms of experience year is shown in Table 3. According to the results of Kruskall Wallis $\mathrm{H}$ test, there is no significant difference in terms of experience year in the subscale of Personal Accomplishment $(\mathrm{p}=.674, \mathrm{p}>.05)$. But, there is significant difference in terms of experience year in the subscales of Emotional Exhaustion $(\mathrm{p}=.002, \mathrm{p}<.05)$ and Depersonalization $(\mathrm{p}=.033, \mathrm{p}<.05)$.

\section{Discussion and Conclusion}

The purpose of this study is to examine the burnout levels of basketball players in terms of gender, age and experience.

Psychological symptoms are less prominent than others that can be seen in individuals who experience burnout. These symptoms are; feeling of frustration and nervousness, feeling of extreme emotional distress and uneasiness, impatience, 
self-reliance, hostility towards the environment, weakness, energy loss, desperation about work, criticizing other people, apathy, increase in family problems, dissatisfaction, negative attitudes towards others, decline in positive emotions such as courtesy, respect and friendship, uncertainty and complexity in thinking, unsubstantiated doubts, depression, feeling of guilty and helplessness (Ardıç ve Polatçı 2008).

According to the results of Mann Whitney $\mathrm{U}$ test, there is no significant difference between male and female basketball players in terms of gender in the subscales of Emotional Exhaustion, Depersonalization and Personal Accomplishment.

Sermon (1994) has investigated the relationship between age, gender, years of experience and burnout levels of secondary school teachers. In the study there was no relationship between demographic variables such as age, gender, and years of experience and burnout levels of teachers.

When the approach model is examined, it can be said that reason for not observing a significant difference in terms of the gender variable may be derived from the basic dynamics, and it is theoretically possible to explain that the sampled area is caused by the variability.

According to the results of Kruskall Wallis $\mathrm{H}$ test, there is no significant difference in terms of age in the subscales of Emotional Exhaustion, Depersonalization and Personal Accomplishment. When literatüre about burnout is examined it is considered to be compatible. According to Unal et al. (2001); burnout is seen at a higher rate in early ages and this is due to the inexperience and inadequacy of the individual. As the age of the individual progresses and the experience increases, the prevalence of burnout decreases. In terms of sports psychology, when concept is evaluated, it is continuous, depends not only on individual effort and prize etc. but also the absence of procedural fees and assignment, suggests that age-related burnout syndrome is not affected in sports

According to the results of Kruskall Wallis $\mathrm{H}$ test, there is no significant difference in terms of experience year in the subscale of Personal Accomplishment But, there is significant difference in terms of experience year in the subscales of Emotional Exhaustion and Depersonalization.

Individual who becomes exhausted are psychologically withdrawn. Psychological withdrawal; entering into superficial relationships, spending time deliberately misplaced in person, distracting, or moving away from the recipient. The consequences of withdrawal are: 1. Low performance, 2. Escape from task, 3. Hiding behind the rules (Maslach, and Jackson, (1981). The relationship between basketball players' burnout and experience concepts is consistent with the reviewed literature. This means that athlete who has acquired experience over time does not feel pressure and stress from training and competition over time.

Within the athlete burnout literature, the knowledge on the prevalence of athlete burnout is mixed and is limited by the sampling procedures used to assess this variable in athlete populations (DeFreese \& Smith, 2013). Accordingly, there are mixed findings in the literature regarding the prevalence of athlete burnout (DeFreese \& Smith, 2013; Gustafsson et al., 2007; Raedeke \& Smith, 2001; Smith, 1986). In 1990, Silva reported that $46.9 \%$ of athletes experienced athlete burnout (Silva III, 1990). Conversely, utilizing a more stringent definition of athlete burnout, Gustafsson et al. (2007) later reported only 1-9\% of athletes have elevated athlete burnout scores (Gustafsson et al., 2007). Consideration of the possible differences in subgroups of athletes by categories such as type of sport, sex, ethnicities and cultures may explain some differences in athlete burnout prevalence (Cresswell \& Eklund, 2005, 2006). For example, it is hypothesized that individual sport participation requires an increased demand of an athlete's time and effort, encouraging the development of athlete burnout (Smith, 1986). Additionally, differences in the prevalence of burnout among 17 individual sports versus team sports may be explained by those participating in team sport having increased opportunities for social support which can act as a buffer against the development of athlete burnout (Coakley, 1992). Individual sport athletes may lack access to social support that can act as a buffer against athlete burnout development, especially in stress-inducing circumstances of sport, such as athletic injury.

The relationship between burnout and experience concepts is consistent with the reviewed literature. According to Turkan (2005); Burnout is a basic concept that emerged in the first and last years of sport in general. It can be interpreted that the phases starting with excitement in the first years of sports and resulting in excessive training reach the degree of fretiness and anxiety over time in the individual. As a result, the level of burnout is important for the experience of basketball players.

Studies will be conducted in the following years may include a survey containing all branches. In addition to burnout syndrome in research, other negative issues experienced by athletes can also be examined. 


\section{References}

Akçamete, G., Kaner, S., \& Sucuoğlu, B. (2001). Burnout, Job Satisfaction and Personality in Teachers, Ankara: Nobel Publishing.

Ardiç, K., \& Polatci, S. (2008). Burnout Syndrome An Application on Academicians (GOÜ Sample), Journal of Faculty of Economics and Administrative Sciences, 10(2), 1-28.

Budak, G., \& Sürvegil, O. (2005). An Application of Academic Staff on the Analysis of Organizational Factors Affecting Burnout, Dokuz Eylül University, I.I.I.B.F. Magazine, 20(2), 95-108.

Büyükzötürk, Ş., Çakmak, E. K., Akgün, Ö. E., Karadeniz, Ş., \& Demirel, F. (2009). Scientific research methods. Ankara: Pegem

Çam, O. (1992). Research on Burnout Syndrome in Nurses. Unpublished PhD Thesis, Ege University Institute of Health Sciences, Izmir.

Çiper, A. (2006). The Impact of Burnout Syndrome on Quality of Service and Call Center Application, Unpublished Master Thesis, Marmara University, Institute of Social Sciences, Istanbul.

Coakley, J. (1992). Burnout among adolescent athletes: A personal failure or social problem. Sociology of Sport Journal, 9(3), 271-285. https://doi.org/10.1123/ssj.9.3.271

Cresswell, S. L., \& Eklund, R. C. (2005). Changes in athlete burnout and motivation over a 12-week league tournament. Medicine \& Science in Sports \& Exercise, 37(11), 1957-1966. https://doi.org/10.1249/01.mss.0000176304.14675.32

Cresswell, S. L., \& Eklund, R. C. (2006). Athlete Burnout: Conceptual Confusion, Current Research and Future Research Directions. In S. Hanton \& S. D. Mellalieu (Eds.), Literature Reviews in Sport Psychology. New York: Nova Science Publishers.

DeFreese, J. D., \& Smith, A. L. (2013). Teammate social support, burnout, and self-determined motivation in collegiate athletes. Psychology of Sport and Exercise. https://doi.org/10.1016/j.psychsport.2012.10.009

Demirtaş, H., \& Güneş, H. (2002). The Dictionary of Educational Administration and Supervision. Ankara: Anı Publishing.

Ergin, C. (1992). Adapting burnout and maslach burnout scale in doctors and nurses. VII. Scientific studies of national psychology congress, 22, 25.

Ersoy, E. (2013). Quantitative research methods. S. Baştürk (Ed.). Scientific research methods(s: 339- 374). inside. Ankara: Vize.

Freudenberger, H. J. (1975). The staff burn-out syndrome in alternative institutions. Psychotherapy: Theory, Research \& Practice, 12(1), 73. https://doi.org/10.1037/h0086411

Goodger, K., Gorely, T., Lavallee, D., \& Harwood, C. (2007). Burnout in sport: A systematic review. Sport Psychologist, 21(2), 127-151. https://doi.org/10.1123/tsp.21.2.127

Gould, D., Udry, E., Tuffey, S., \& Loehr, J. (1996). Burnout in competitive junior tennis players: I. A quantitative psychological assessment. The Sport Psychologist.

Gustafsson, H., Kenttä, G., Hassmén, P., \& Lundqvist, C. (2007). Prevalence of burnout in competitive adolescent athletes. Sport Psychologist, 21(1), 21-37. https://doi.org/10.1123/tsp.21.1.21

Kervanc1, F. (2013). A Research on Determining the Effect of Burnout Syndrome on Organizational Commitment and Job Separation Intention. Published Doctorate Thesis, Niğde University, Institute of Social Sciences, Niğde.

Lemyre, Pierre-Nicolas, R., Glyn, C., \& Stray-Gundersen, J. (2007). Motivation, overtraining, and burnout: Can self-determined motivation predict overtraining and burnout in elite athletes? European Journal of Sport Science, 7(2), 115-126. https://doi.org/10.1080/17461390701302607

Marshall, R. E., \& Kasman, C. (1980). Burnout in the neonatal intensive care unit. Pediatrics, 65(6), 1161-1165.

Maslach, C., \& Jackson, S. E. (1981). MBI: Maslach burnout inventory. Palo Alto, CA, 1(2), 49-78.

Pines, A., \& Aranson, E. (1988). Career Burnout, Couses and Cures, The Free Press: New York.

Pines, A., \& Maslach, C. (1978). Characteristics of staff burnout in mental health settings. Hospital \& Community Psychiatry. https://doi.org/10.1176/ps.29.4.233

Raedeke, T. D, \& Smith, A. L. (2009). The athlete burnout questionnaire manual (Vol. 4): Fitness Information Technology.

Raedeke, T. D. (1997). Is athlete burnout more than just stress? A sport commitment perspective. Journal of sport \& 
exercise psychology. https://doi.org/10.1123/jsep.19.4.396

Raedeke, T. D., \& Smith, A. L. (2001). Development and preliminary validation of an athlete burnout measure. Journal of sport \& exercise psychology. https://doi.org/10.1123/jsep.23.4.281

Sarikaya, P. (2007). Personality Traits of the Burnout Syndrome Relating to Locus of Control and an Application, Unpublished Master Thesis. Marmara University, Istanbul.

Schuster, N. D., Nelson, D. L., \& Quisling, C. (1984). Burnout among physical therapists. Physical Therapy, 64(3), 299-303. https://doi.org/10.1093/ptj/64.3.299

Sermon, J. M. (1994). The relationship of the dual role assignment to the level of perceived burnout by secondary teachers. Unpublished doctoral dissertation, Florida State University, Tallahassee.

Silva III, J. M. (1990). An analysis of the training stress syndrome in competitive athletics. Journal of Applied Sport Psychology, 2(1), 5-20. https://doi.org/10.1080/10413209008406417

Smith, R. E. (1986). Toward a cognitive-affective model of athletic burnout. Journal of Sport Psychology, 8(1), 36-50. https://doi.org/10.1123/jsp.8.1.36

Sürgevil, O. (2005). Working Life Burnout Syndrome: Coping Techniques with Burnout, Nobel Publication: Ankara.

Turkan, S. (2005). Psychological Symptoms of Teachers Burnout and Coping Behaviors. Unpublished PhD Thesis. Pamukkale University, Institute of Educational Sciences, Denizli.

Ünal, S., Karlıdağ, R., \& Yoloğlu, S. (2001). Relation of Life Satisfaction Levels and Burnout and Job Satisfaction Levels in Docs, Clinical Psychiatry, 4(2), 113-118.

Wolfe, G. A. (1981). Burnout of Therapists Inevitable or Preventable? Physical Therapy, 61(7), 1046-1050. https://doi.org/10.1093/ptj/61.7.1046

Wright, T. A., \& Bonett, R. (1997). The Contribution of Burnout to Work Performance. Journal of Organizational Behavior, 18(5), 491-499. https://doi.org/10.1002/(SICI)1099-1379(199709)18:5<491::AID-JOB804>3.0.CO;2-I

Yıldırım, F. (1996). The Relation Between Job Satisfaction and Perceived Role Conflict and Burnout in Bank Employees. Unpublished Master's Thesis, Hacettepe University, Institute of Social Sciences, Ankara.

\section{Copyrights}

Copyright for this article is retained by the author(s), with first publication rights granted to the journal.

This is an open-access article distributed under the terms and conditions of the Creative Commons Attribution license which permits unrestricted use, distribution, and reproduction in any medium, provided the original work is properly cited. 